\title{
Effect of Catching Surface and Tilt Angle on Bruise Damage of Sweet Cherry
}

\section{due to Mechanical Impact}

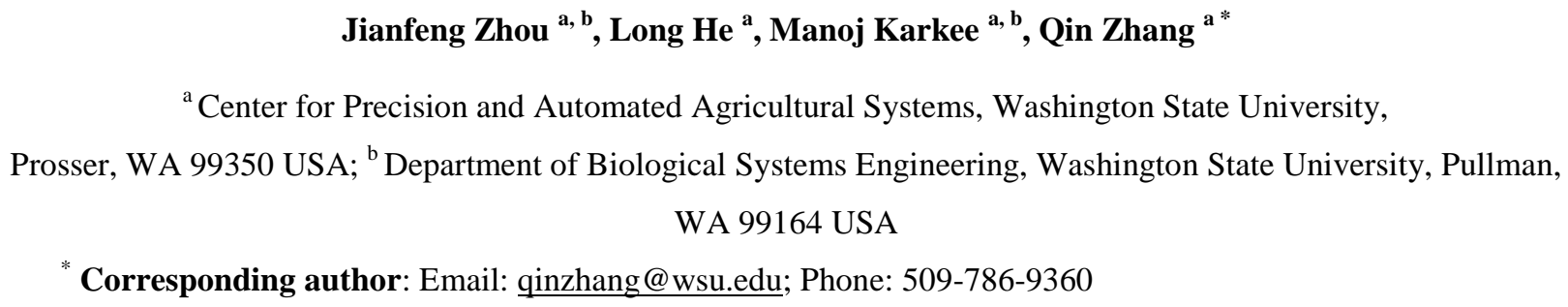

\section{Abstract}

Fruit bruise damage induced by mechanical impact is the most critical obstacle for the application of mechanical harvesting on fresh-market sweet cherries. One of main sources of fruit bruise is the mechanical impact by fruit catching surfaces occurring in fruit collection during mechanical harvesting. The goal of this research was to investigate the effect of cushion material, fruit drop height, and tilt angle of catching surface on fruit bruise damage. Three catching surfaces with five tilt angles from $0^{\circ}$ to $60^{\circ}$ were used to catch fruits freely dropped from heights of 0.3 to $2.1 \mathrm{~m}$. The impact force and deformation of cushion materials was measured by a force sensing unit and a high speed camera, respectively. Results showed that maximum impact force increased linearly with drop height and was reduced by cushion materials with sufficient thickness. The fruit damage percentages of cushion material 1 and 2 were $25.0 \%$ $89.0 \%$ and $72.0 \%-100.0 \%$ less than that of non-cushion material at drop height of 0.3 to $2.1 \mathrm{~m}$ at $0^{\circ}$ tilt angle, respectively. Results also shown catching surfaces with tilt angle reduced bruise damage substantially. Damage percentage of catching surfaces at $60^{\circ}$ tilt angle was around $75.0 \%$ less than that at $0^{\circ}$ non-cushion and cushion material when fruit were dropped from 1.5

$\mathrm{m}$. The results show that catching surfaces with cushion materials at a tilt angle of $60^{\circ}$ might be a promise for mechanical harvesting of fruits with low fruit bruise damage. 
Keywords: Fruit quality; mechanical harvesting; cushion material; catching surface

\section{Introduction}

The consumption of fresh market sweet cherry (Prunus avium L.) has been increasing rapidly around the world in recent years (USDA-ERS, 2012). In U.S, good return and profit margin has led to a substantial increase in planting acreage from 24,300 ha in 2000 to 34,400 ha in 2009 (USDA-ERS, 2012). Currently, all the freesh-market sweet cherry is harvested by seasonal pickers. However, decreasing labor availability and increasing labor cost have been one of the most critical challenges for sweet cherry growers. Especially, the increased labor cost is sustanaible. Development and adoption of mechanical harvesting technologies is becoming essential to address these labor-related issues in sweet cherry and other tree fruit production. Mechanical harvesting of tree fruit crops, including sweet cherry, has been investigated for many decades (Adrian et al., 1965, Pellerin et al., 1982, Peterson and Brown, 1996, Erdoğan et al., 2003, Polat et al., 2007, Zhou et al., 2013), but the commercial adoption for fresh market fruit is still lacking. One of the obstacles for adopting mechanical harvesting to fresh market sweet cherry and other tree fruit is the harvest-induced fruit damage. In an early trail of mechanical harvesting of sweet cherry, Halderson (1966) used a commercial nut shaker and found that the damage percentage of machine harvested fruit was three times higher than that of hand picking. More recently, Peterson et al. (2003) developed a new limb knocker to harvest fresh-market tree fruit including cherry and apple. The authors reported that only 58.0-64.0\% of fruit achieved marketable quality in the trail of harvesting "Bing" sweet cherries. Chen et al. (2012) reported an average fruit damage percentage of $23.9 \%$ in a field test using a hand-held 
49 vibratory harvester to harvest sweet cherry. Zhou et al. (2014) found that the mechanical

50 harvester could remove more than $90.0 \%$ of fresh cherries from tree branches if suitable

51 excitation positions were selected, but around $29.0 \%$ fruit were bruised during harvesting. These

52 reports indicated that the high fruit damage percentage of sweet cherry using mechanical

53 harvesting technologies is still the key issue that needs to be addressed.

$54 \quad$ Harvest-induced fruit damage is mainly caused by mechanical impact of fruit-to-fruit or

55 limb-to-fruit contacts, which happens in detaching process and/or during fruit catching (Norton

56 et al., 1962; Markwardt et al., 1964; Opara and Pathare, 2014). Trees in sweet cherry orchards of

57 Northwest Pacific region of U.S. are usually 3 - $5 \mathrm{~m}$ in height, and $2-5 \mathrm{~m}$ in width (Ampatzidis

58 and Whiting, 2013). Fruits mechanically detached from these trees will fall down from the height

59 of up to $2 \mathrm{~m}$ before caught by catching surfaces. To reduce fruit damage, fruit catching surfaces

60 are padded with various impact absorbing materials (cushion materials) during harvesting

61 (Erdoğan et al., 2003). Erdoğan et al. (2003) found that fruit damage reduced 30.0\% when 20-

$62 \mathrm{~mm}$ canvas material was put on the ground during mechanical harvesting of apricots. Xu et al.

63 (2015) also found that mechanical impact of blue berries was reduced significantly by using

64 cushion materials on packing lines. The basic principle of using cushion materials is to absorb

65 the kinetic energy, which can result in bruise damage when exceeds a threshold for tissue failure

66 (Van linden et al., 2006a). Different cushion materials have different firmness, density and

67 elasticity and will perform differently in reduction of fruit bruise damage (Jarimopas et al., 2007;

68 Ahmadi et al., 2010). Clark (1971) used two types of polyurethane foam to form low-impact fruit

69 cushion surfaces to reduce the mechanical impact in catching falling peaches, and found that

70 catching surfaces with a wedge shape had low impact force and less rebound height. Through a

71 theoretical analysis of extended Hertz contact theory, Horsfield et al. (1972) found that a material 
72 with a low modulus of elasticity could more effectively reduce the impact-induced peach bruise 73 damage while using the material to catch the falling fruit.

Other than the cushion materials to absorb mechanical impact energy, there is also a

75 potential to reduce mechanical impact by adjusting tilt angle of catching surface. In fully

76 mechanical harvesting system of cherries, fruit catching devices were often made of a set of

77 catching plates covered with cushion materials, with the catching surface usually tilted at an

78 angle for collecting fruits (Peterson et al., 2003; Torregrosa et al., 2006). However, no researches

79 were condcuted to determine how tilte angle of fruit catching devices affects the fruit damage. In

80 this research, a laboratory experiment was designed to study the aforementioned factors of

81 cushion materials and tilt angle of catching surface affecting the bruise damage. A laboratory

82 scale fruit catching system was developed to mimic the fruit catching process, and determine the

83 effect of fruit drop height, cushion materials and tilt angle on bruise damage of sweet cherries.

84 The specific objectives of this research are: (1) to develop a fruit impact sensing system to

85 measure the impact force and deformation of cushion material in fruit catching process; and (2)

86 to determine the effect of cushion material, fruit drop height, and tilt angle of catching surface on

87 bruise damage of sweet cherries.

\section{Materials and Methods}

$89 \quad 2.1$ Development of experimental system

In this study, a laboratory-scale fruit catching frame was designed and fabricated (Figure

91 1). This research platform consisted of four functional parts: i) a fruit guidance tube, ii) a fruit

92 catching plate, iii) an impact force sensing unit, and iv) an image acquisition unit. The guidance

93 tube was adjustable in both vertical direction (from 0 to $3.0 \mathrm{~m}$ above the catching plate) and

94 horizontal direction. The guide tube allowed cherry samples in one treatment to be dropped from 
exactly the same height and guided to same target zone of the fruit catching plate. The catching plate was made of aluminum material, where the sensing unit was mounted underneath (Figure 1a). The tilting setup of the catching plate was shown in Figure 1b, which shows that one end of the catching plate (aluminum material) was attached to the impact force sensor and another end was hinged to the frame. By adjusting the position of the hinge and sensor location, the catching frame could be adjusted from $0^{\circ}$ to $90^{\circ}$ from the ground level. The different foams (cushion materials hereafter) would be attached on the surface of the catching plate (non-cushion material hereafter) to reduce fruit bruise damage.
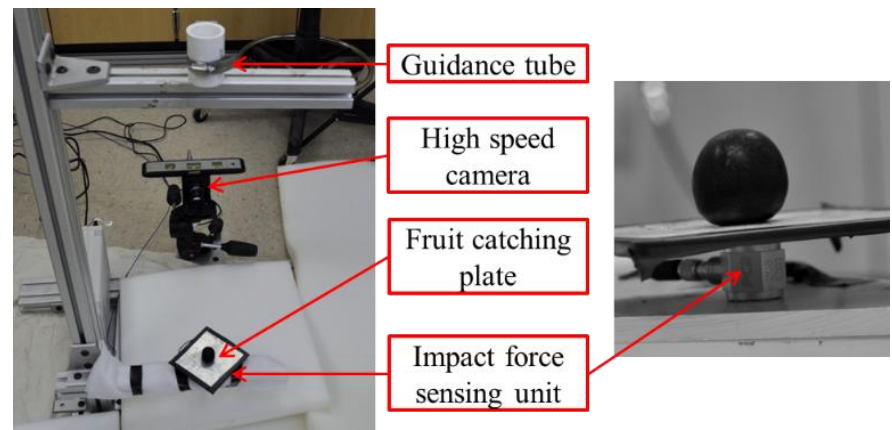

(a) Horizontal setup

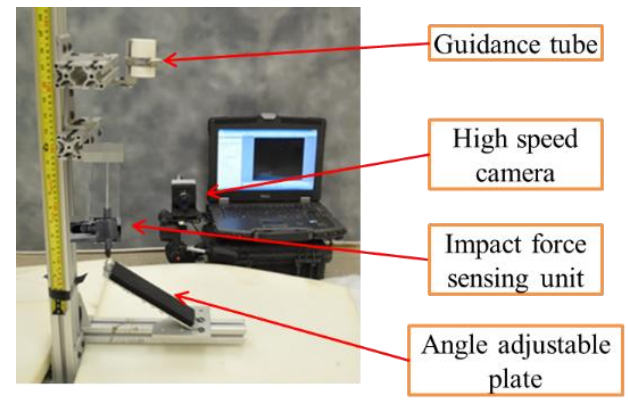

(b) Tilting setup

Figure 1. Illustration of the fruit catching research platform. Figure (a) shows that a fruit catching plate was mounting on the impact force sensor, which was fixed on an aluminum structure horizontal to ground level. Figure (b) shows that fruit catching plate was tilting an angle to ground surface.

To study mechanical impact force on the fruit bruise damage, a pendulum impactor is commonly used for impact tests in many researches (Van linden et al., 2006b; Opara et al., 2007), where a fruit was attached to the end of a pendulum arm and hits on a sensing unit to measure impact force. This method is suitable for measure the impact force, but it is difficult to detect the force of a fruit falling on a tilting catching surface. In this test, a mechanical impact sensing system was developed, which included an impact force sensing unit (208C02, PCB Piezotronics, Depew, NY), a signal conditioner (482A21, PCB Piezotronics, Depew, NY), an analog signal acquisition module (NI 9205, National Instruments, Austin, TX) and associated software. The impact force unit is a calibrated $\mathrm{ICP}^{\circledR}$ force sensor with upper frequency response of $36 \mathrm{kHz}$ and 
non-linearity of less than $1.0 \%$. The NI signal acquisition module is a high resolution analog input module with 16-bit resolution and $250 \mathrm{kHz}$ sample rate. The impact force was sampled at a rate of $10 \mathrm{kHz}$ in this study. At same time, a high speed camera (HiSpec 1, Fastec Imaging, San Diego, CA) was used to record the impact process of cherry fruits hitting on catching surface at the rate of 1,500 frames per second (fps). The high speed images were used to quantify the deformation of cushion materials and tracking the impact position of fruits.

\subsection{Sample preparation and experimental design}

Fruit samples were manually picked from 11-year-old "Skeena" cherry trees at commercial harvesting time in an orchard near Sunnyside, WA, USA. Samples were selected with a cherry color chart (Cerise, Centre Technique Interprofessionel des Fruit et Légumes, Paris, France) and only those with skin color of approximate six grade were chosen. All fruits were carefully picked in the morning time when they were firm to avoid bruise damage and were processed timely in the same day. Approximate 1200 visually selected defect-free fruit samples were selected from those hand-picked fruits and were randomly divided into 45 groups with 25 fruits in each group. Each fruit sample was weighted, labeled and followed by firmness test with a firmness tester (Firm Tech 2, Bio Works, Wamego, Kansas). The firmness tester measures the fruit firmness using the force-deformation response from a cherry fruit compressed across fruit cheeks with deformation of $1 \mathrm{~mm}$. This firmness tester is a widely used non-destructive instrument for testing the firmness of soft fruit (such as cherry, berry) in quality assessment research (Hampson et al., 2014; Mezzetti, 2013). The tester was also used to monitor the change of fruit firmness continually (Yang et al., 2008; Schrader, 2005) and no report indicated significant quality change in the test fruits. The average firmness and average weight of fruits in a group was listed in Table 1. With the ANOVA test descripted in section 2.5, it is found that 
142

143

144

145

146

147

148

149

there was no difference in average firmness and weight of fruits among those test groups. All the prepared samples were kept in the preparation room with room temperature of $21.0^{\circ} \mathrm{C}$ and

relative humidity $(\mathrm{RH})$ of around $60.0 \%$. The same room condition was also applied to the room

of experiment. To avoid the development of further damage, the prepared fruit samples were

tested in the same day as they were sampled.

Table 1. Average and standard deviation of fruit weight and firmness in each test group. No significant difference was found among between groups in fruit weight and firmness.

\begin{tabular}{cccccc}
\hline & \multicolumn{2}{c}{ July 16, Steel } & \multicolumn{3}{c}{ July 17, Form 1 } \\
\hline Group & $\begin{array}{c}\text { Weight, } g \\
\text { (ave } \pm \text { s.d.) }\end{array}$ & $\begin{array}{c}\text { Firmness, } g / m m \\
\text { (ave } \pm \text { s.d.) }\end{array}$ & Group & $\begin{array}{c}\text { Weight, } g \\
\text { (ave } \pm \text { s.d.) }\end{array}$ & $\begin{array}{c}\text { Firmness, } g / m m \\
\text { (ave } \pm \text { s.d.) }\end{array}$ \\
\hline 1 & $10.8 \pm 2.2$ & $287.0 \pm 25.4$ & 20 & $10.9 \pm 1.2$ & $290.3 \pm 33.7$ \\
2 & $11.7 \pm 1.2$ & $295.2 \pm 45.3$ & 21 & $11.5 \pm 1.4$ & $282.7 \pm 27.9$ \\
3 & $11.7 \pm 1.3$ & $297.8 \pm 38.2$ & 22 & $10.9 \pm 2.7$ & $288.4 \pm 39.4$ \\
4 & $11.5 \pm 1.2$ & $280.8 \pm 34.5$ & 23 & $10.7 \pm 1.5$ & $297.2 \pm 28.2$ \\
5 & $10.5 \pm 1.4$ & $282.6 \pm 27.5$ & 24 & $11.2 \pm 1.3$ & $286.0 \pm 25.9$ \\
6 & $10.9 \pm 2.2$ & $296.1 \pm 38.4$ & 25 & $11.7 \pm 1.0$ & $290.5 \pm 26.2$ \\
7 & $10.4 \pm 1.6$ & $289.6 \pm 39.3$ & 26 & $11.4 \pm 1.2$ & $288.8 \pm 35.5$ \\
8 & $10.6 \pm 1.3$ & $287.1 \pm 24.5$ & 27 & $11.2 \pm 1.7$ & $291.1 \pm 25.4$ \\
9 & $11.1 \pm 1.8$ & $288.2 \pm 33.8$ & 28 & $10.9 \pm 2.2$ & $288.1 \pm 27.9$ \\
10 & $11.0 \pm 2.1$ & $292.8 \pm 29.2$ & 29 & $11.1 \pm 1.5$ & $291.7 \pm 30.8$ \\
11 & $10.2 \pm 1.4$ & $303.6 \pm 33.5$ & 30 & $10.9 \pm 0.8$ & $290.9 \pm 23.9$ \\
12 & $10.6 \pm 1.1$ & $295.1 \pm 37.6$ & 31 & $11.1 \pm 1.1$ & $283.0 \pm 29.6$ \\
13 & $10.2 \pm 1.1$ & $284.7 \pm 24.5$ & 32 & $10.1 \pm 1.2$ & $307.2 \pm 39.4$ \\
14 & $11.2 \pm 0.8$ & $301.1 \pm 29.1$ & 33 & $11.3 \pm 0.7$ & $279.4 \pm 38.1$ \\
15 & $10.9 \pm 1.0$ & $288.6 \pm 30.1$ & 34 & $11.5 \pm 1.0$ & $279.4 \pm 42.7$ \\
16 & $10.8 \pm 0.9$ & $289.7 \pm 26.3$ & 35 & $11.4 \pm 0.8$ & $273.7 \pm 36.6$ \\
17 & $11.2 \pm 0.8$ & $269.2 \pm 33.7$ & 36 & $11.2 \pm 0.9$ & $302.6 \pm 30.5$ \\
18 & $10.9 \pm 0.9$ & $282.1 \pm 27.1$ & 37 & $10.7 \pm 0.6$ & $273.7 \pm 31.0$ \\
19 & $10.9 \pm 1.0$ & $295.5 \pm 30.5$ & 38 & $11.9 \pm 0.9$ & $298.3 \pm 35.8$ \\
& & & & &
\end{tabular}

July 18 , Form 2

\begin{tabular}{cccccc}
\hline Group & $\begin{array}{c}\text { Weight, } g \\
\text { (ave } \pm \text { s.d.) }\end{array}$ & $\begin{array}{c}\text { Firmness, } g / m m \\
\text { (ave } \pm \text { s.d.) }\end{array}$ & Group & $\begin{array}{c}\text { Weight, } g \\
\text { (ave } \pm \text { s.d.) }\end{array}$ & $\begin{array}{c}\text { Firmness, } \\
g / m m \text { (ave } \pm \\
\text { s.d.) }\end{array}$ \\
\hline 39 & $11.3 \pm 0.8$ & $277.1 \pm 51.7$ & 43 & $11.3 \pm 1.0$ & $287.1 \pm 25.5$ \\
40 & $11.1 \pm 1.2$ & $286.0 \pm 45.3$ & 44 & $11.1 \pm 0.8$ & $285.0 \pm 25.0$
\end{tabular}


In this study, three external factors related to mechanical induced fruit damage were

152 investigated, i.e. drop height, cushion material and tilt angle. The test drop height in this study 153 was selected from 0.3 to $2.1 \mathrm{~m}$ according to the potential falling height in orchard condition of

154 Washington State. The used cushion materials were two off-the-shelf foams, which were

155 commonly used as buffering material for packaging and damage prevention. Table 2 lists the major parameters of these cushion materials, including the firmness, density, and thickness.

157 Normally, a fruit catcher with the tilt angle more than $60^{\circ}$ would hardly fit into a cherry canopy 158 and would be difficult to catch most of the detached fruit. Therefore, the tilt angles of catching 159 plate were designed as $15^{\circ}, 30^{\circ}, 45^{\circ}$ and $60^{\circ}$. As reference, all the treatments designed for 160 cushion materials were also repeated with bared catching plate (non-cushion material), which 161 was made of a piece of aluminum material. The experimental configuration was shown in Table 1623.

Table 2. Specifications of cushion materials used in the research*

\begin{tabular}{lcc}
\hline Cushion Material & Cushion material 1 & Cushion material 2 \\
\hline $\begin{array}{l}\text { Firmness }(25 \% \\
\text { deflection, } k P a)\end{array}$ & 4.1 & 31.0 \\
Density $\left(\mathrm{kg} \cdot \mathrm{m}^{-3}\right)$ & 28.8 & $112-160$ \\
Thickness $(\mathrm{mm})$ & 6.4 & 9.5 \\
Description & Soft & Firm \\
\hline ameters were from online documents provided by suppliers (McMaster-Carr, 2013)
\end{tabular}

Table 3. Experimental configuration

\begin{tabular}{cccc}
\hline Material & Tilt angle & $\begin{array}{c}\text { Drop height with 0.3 } \\
\text { increment }(\mathrm{m})\end{array}$ & Group No. \\
\hline $\begin{array}{c}\text { Non- } \\
\text { cushion }\end{array}$ & $0^{\circ}$ & $0.3-2.1$ & $1-7$ \\
& $15^{\circ}, 30^{\circ}, 45^{\circ}, 60^{\circ}$ & $0.3-1.5$ & $8-19$ \\
\hline
\end{tabular}




\begin{tabular}{cccc}
\cline { 2 - 4 } Cushion I & $0^{\circ}$ & $0.3-2.1$ & $20-26$ \\
& -- & -- & -- \\
\cline { 2 - 4 } Cushion II & $0^{\circ}$ & $0.3-2.1$ & $27-33$ \\
& $15^{\circ}, 30^{\circ}, 45^{\circ}, 60^{\circ}$ & $0.3-1.5$ & $34-45$ \\
\hline
\end{tabular}

2.3 Fruit damage assessment

Bruise damage of cherry fruit is hard to be identified immediately after mechanical impact (Van linden et al., 2006a). However, a soft flattened surface would develop in the damaged area on the fruit after a few days (Thompson et al., 1997). To allow the development of such bruise indicating surfaces, all fruit samples were stored in a cold room for one week right after the dropping test. To identify the damaged, the fruit samples were checked using both

173 finger touching and visual observation after they were taken out from the cold room (Thompson

175 fruit with catching surface was determined using high-speed camera images, and only bruise

177 regions were marked using a mark pen for further processing (Figure 2a).

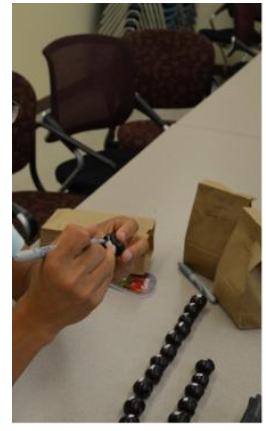

(a)

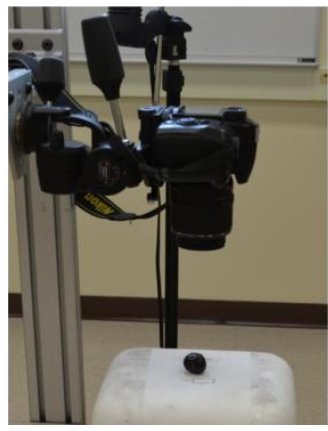

(b)

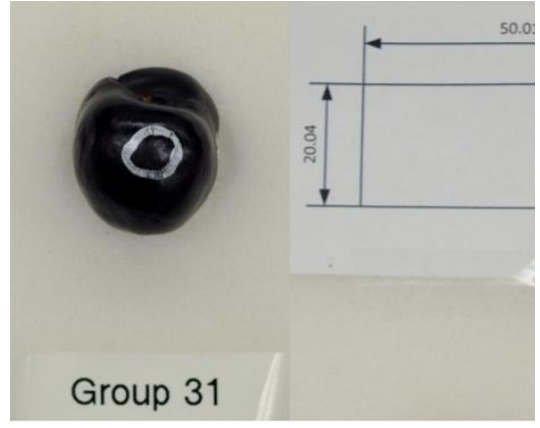

(c)

Figure 2. The procedure of assessing fruit bruise area: (a) marking bruise region around contact point of fruit to catching surface with the assistant of high speed images; (b) taking image of fruit with marked region facing up and perpendicular to the camera; and (c) one example of images used for measuring the bruise area. A reference rectangle with the dimension of $20.0 \times 50.0 \mathrm{~mm}$ was used for length calibration. 
To measure the bruise areas on fruit samples, a digital camera (D5000, Nikon, Melville,

$186 \mathrm{NY}$ ) was used to take the images of fruit with aforementioned marked region by placing the

187 damaged area facing towards the camera lens (Figure 2b). A pre-defined calibration rectangle of

$18820.0 \times 50.0 \mathrm{~mm}$ was put near the samples as shown in Figure $2 \mathrm{c}$. The total number of pixels of

189 the bruise area was counted from the acquired images and then converted into actual bruise area

190 using the following equation:

$$
A=\frac{N_{d}}{N_{r}} \times A_{r}
$$

192 where, $A$ is the bruise area of a fruit $\left(\mathrm{mm}^{2}\right), N_{d}$ is the total number of pixels in the identified

193 bruise area, $N_{r}$ is the total number of pixels in the reference rectangle, and $A_{r}$ is the area of the

194 reference rectangle $\left(50.0 \times 20.0=1000.0 \mathrm{~mm}^{2}\right)$. An open source software ImageJ (Version $1.47 \mathrm{f}$,

195 National Institutes of Health, Bethesda, MD) was used to count the total number of pixels in both

196 the damaged area and the reference rectangle.

197 According to the USDA standards for sweet cherry grading (USDA-AMS, 1990) and the

198 "Shipping Point and Market Inspection Instructions" (USDA-AMS, 2005), a cherry fruit is

199 considered damaged if the bruise area aggregates to more than $6.4 \mathrm{~mm}$ in diameter $\left(32.2 \mathrm{~mm}^{2}\right.$ in

200 area), and seriously damaged fruit when affected area is more than $9.5 \mathrm{~mm}$ in diameter $(70.8$

$201 \mathrm{~mm}^{2}$ in area). The percentage $\left(P_{d}\right)$ of damaged fruit (with bruise area larger than $32.2 \mathrm{~mm}^{2}$ ) was

202 then calculated as follows.

$$
P_{d}=\frac{N_{2}}{N_{1}} \times 100
$$

204 where, $P_{d}$ is the damage percentage, $N_{2}$ is the number of damaged fruit, and $N_{1}$ is the total 205 number of fruits in a test group (25 fruits). 

cushion material 2.

Cherry fruits usually carry a large amount of kinetic energy when it is detached from the tree before reaching the catching surface. Cushion materials can absorb a portion of kinetic/potential energy of cherry fruits to reduce the mechanical impact force (stress) to fruits themselves. The capability of cushion materials in reducing bruise damage is determined by the property of the materials. An typical stress-strain characteristics of a cushion material is shown in Figure 3 (Avalle et al., 2001), which includes three definite regions, i.e. linear elasticity, plateau and densification. When the compressive stress is small (and therefore strain is small), the cell walls of the cushion material will bend and exhibit a linear elasticity. As the stress increases, for example due to increased impact force, the cell walls will collapse by elastic buckling and plastic yielding consecutively. Finally, if the strain caused is large enough to bring opposite cell walls meet each other, the cushion material will lose its function as a buffering material, and only a small additional strain will result in a sharp increase in stress beyond that point. As the material specifications provided in Table 2, cushion material 2 has a larger density and firmness than cushion material 1 , which resulted in a higher stress-strain curves than that of cushion material 1 . To absorb the same amount of mechanical impact energy, soft material of cushion material 1 will have a larger deformations (compressive strain) than the firm material of 

material and deformation of the cushion material $(\mathrm{mm})$. cushion material:

$$
\varepsilon=\frac{b}{a} \times 100 \%
$$

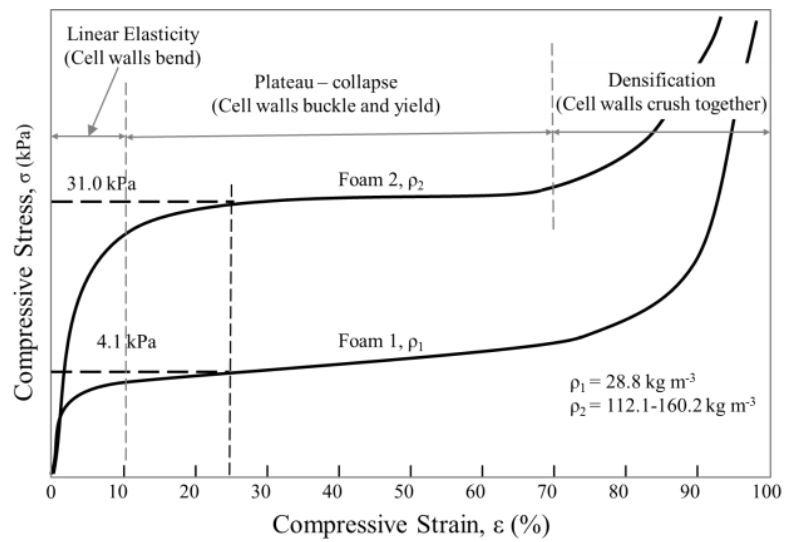

Figure 3. The stress-strain curve for the two cushion materials used in this study.

To estimate the deformation (compressive strain) in the fruit catching process, the deformation of the cushion materials and fruit was measured based on the geometric center change of a fruit in high speed images. Figure 4 illustrates how to measure the deformation of fruit and cushion material, where ' $a$ ' is the thickness of cushion material, $b$ is the deformation of cushion material (mm) and $c$ is the overall deformation of the cushion material and the fruit (mm). The overall deformation $c$ is determined by the moving distance of the top point of a cherry fruit when the fruit just touches the cushion material's surface to the point when it reaches the lowest position. Then the deformation of the fruit will be the difference of the overall deformation and the deformation of cushion material, i.e. $(c-b)$. The compressive strain of each cushion material was calculated using the percentage of deformation to the thickness of the

where, $\varepsilon$ is the compressive strain of a cushion material $(\%), a, b$ are the thickness of the cushion 

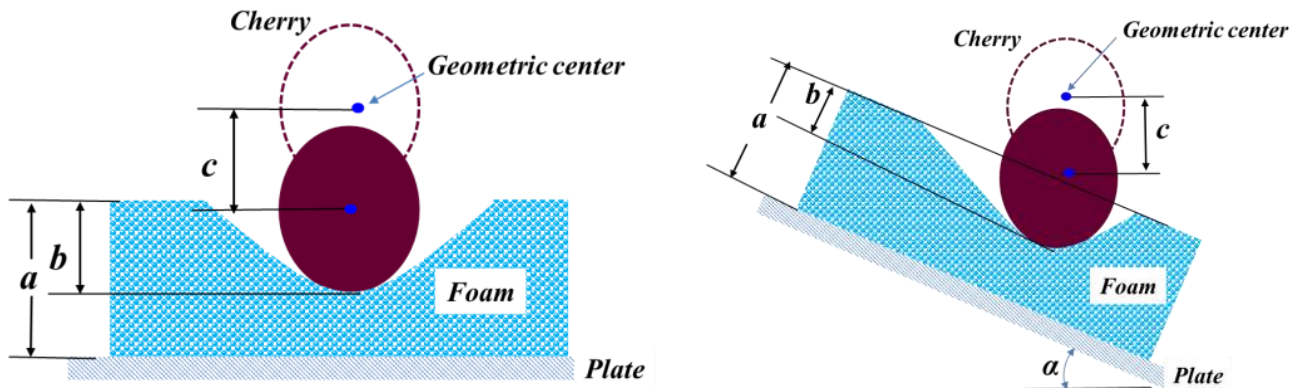

Figure 4. Overall deformation of fruit and catching surface; $a$ is the thickness of the cushion material (mm), $b$ is the deformation of cushion material and $c$ is the overall deformation of the cushion material and the fruit. The fruit deformation is the difference of $c$ and $b$, i.e. $(c-b)$.

camera images using the image processing toolbox of Matlab (R2011b, The MathWorks, Natick, MA). Before test, a tape measure with $1.0 \mathrm{~mm}$ accuracy was put in the center of catching surface to decide the ratio of pixel and physical distance (unit: $\mathrm{mm} / \mathrm{pix}$ ), which was used to calculate the physical distance between fruit centers in consecutive images.

\subsection{Statistical Analysis}

SAS® (ver. 9.2, SAS Institute, Cary, NC, USA) was used to perform descriptive and ANOVA analysis, as well as linear regression. Raw data of maximum impact force were plotted using box-and-whiskers plots, and outliers in the data were identified using the BOXSTYLE = SCHEMATICID option. Outliers were usually caused in the condition of fruits fell on the edge of fruit catching plate and were removed for further statistical analysis. The "PROC REG" procedure with "stepwise" method was used to setup the regression relationship between maximum impact force and drop height and fruit weight. The significance of difference in means of different parameters from different treatments was assessed using ANOVA ('PROC GLM') analysis in SAS ${ }^{\circledR}$. Least square mean difference ('LSMEANS/PDIFF') option was used to compare the treatment multiple comparison of means at 0.05 level of significance. The output data were plotted using SigmaPlot ${ }^{\circledR}$ Ver. 11.0 (Systat Software Inc., San Jose, CA). 


\section{Results and Discussion}

2673.1 Impact force and deformation of cushion materials

The regression between maximum impact force and factors of drop height and fruit 269 weight was tested using $\mathrm{SAS}^{\circledR}$, which shows that there was no statistical effect of fruit weight on 270 impact force ( $p>0.1$ for all catching surfaces). The potential reason is that the average fruit 271 weight of each group was not significantly different. Therefore the maximum impact force was

272 mainly determined by the factor of drop height. Figure 5 presents the means of maximum impact

273 forces over a sample group (25 fruits) against the drop heights measured on three different

274 catching surfaces. The lines in the figure were fitted using linear relationship and their

275 coefficients of determination $\left(R^{2}\right)$ were $0.99,0.98$ and 0.96 , respectively for cushion material 1 , 276 cushion material 2 and non-cushion material (bare plate). As shown in the figure, the average

277 maximum impact force resulted from cushion material 1, cushion material 2 and non-cushion

278 surface increased from 8.4, 16.2 and $27.7 \mathrm{~N}$ to $94.0,80.4$ and $91.5 \mathrm{~N}$, respectively, as the drop

279 height increased from 0.3 to $2.1 \mathrm{~m}$. The results indicate that the average maximum impact force 280 measured was linearly determined by the drop height. It is also found that the average maximum 281 force of non-cushion material was always higher than that of both cushion materials, indicating 282 the ability to reduce the impact force with cushion materials (Brown et al., 1996). 


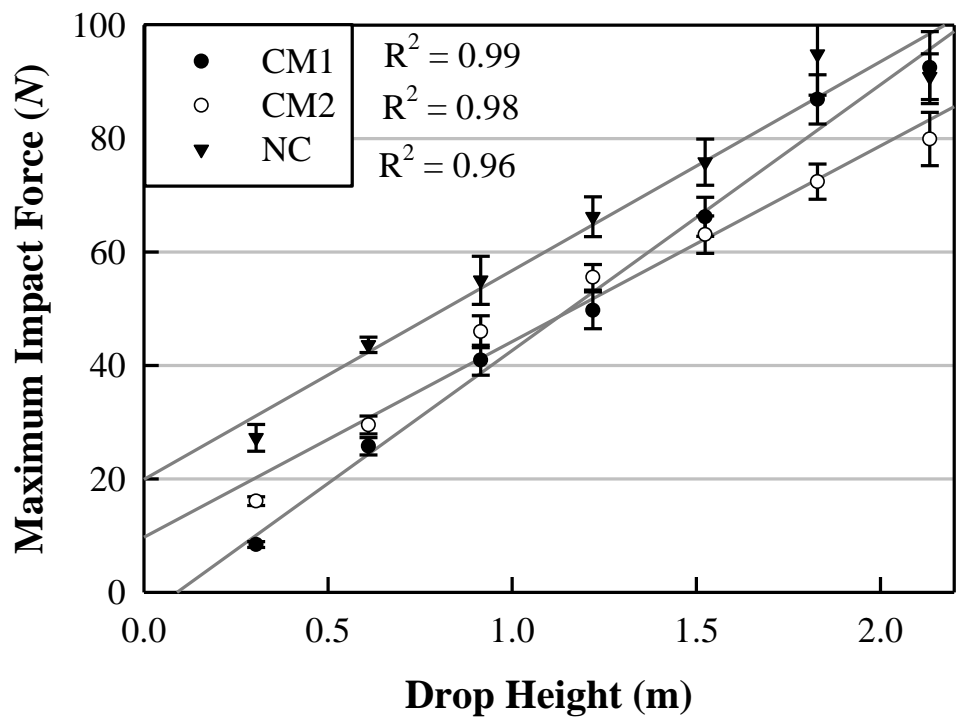

Figure 5. The average maximum impact force with standard deviation bars of 25 fruits regarding of different materials over the dropping height of 0.3 to $2.1 \mathrm{~m}$. In the figure, $\mathrm{CM}$ - cushion material, NC - noncushion material.

The capacity of cushion materials for reducing impact force was different, determined by their firmness, density and thickness (Avalle et al., 2001). From Figure 5 it is found that impact force on the softer cushion material 1 was lower than that of firmer cushion material 2 at low drop height $(<=1.2 \mathrm{~m})$. The result agreed with the findings of Horsfield et al. (1972) that materials with lower elasticity were more effective in reduce of impact-induced fruit bruise damage. However, with the increase of drop height $(>1.5 \mathrm{~m})$, the impact force of lower firmness cushion material 1 was starting passing that of cushion material 2 and was approaching to the value of non-cushion material. This is because that compressive stress (impact force) of cushion material was highly related to the compressive strain (deformation) as shown in Figure 3. The compressive strain of two cushion materials at different drop heights was calculated based on deformation of cushion materials using Eq. 3 and the average value of each group was presented in Figure 6. The compressive strain of cushion material 1 was $72.6 \pm 5.2 \%, 90.0 \pm 6.1 \%$ and 96.0 $\pm 8.3 \%$ at the drop heights of $0.3,0.9$ and $1.5 \mathrm{~m}$, respectively, which was significantly larger than 
$36.9 \pm 3.1 \%, 44.0 \pm 5.0 \%$ and $58.8 \pm 9.2 \%$ of cushion material 2 . The higher the drop height, the significantly larger deformation generated in both materials, which would result in larger stress (impact force). According to the stress-strain curve in Figure 3, the compressive stress of soft cushion material 1 is consistently less than that of cushion material 2 when the strain (deformation) is less than $90.0 \%$. However, the stress level would increase dramatically in both materials when the strain is over $90.0 \%$. Therefore, when the compressive strain of cushion material 1 reach to $90.0 \%$ and $96.0 \%$ at the drop height of 0.9 and $1.5 \mathrm{~m}$ (Figure 6), respectively, the maximum impact force increased sharply to exceed the value of cushion material 2, as shown 309 in Figure 5.

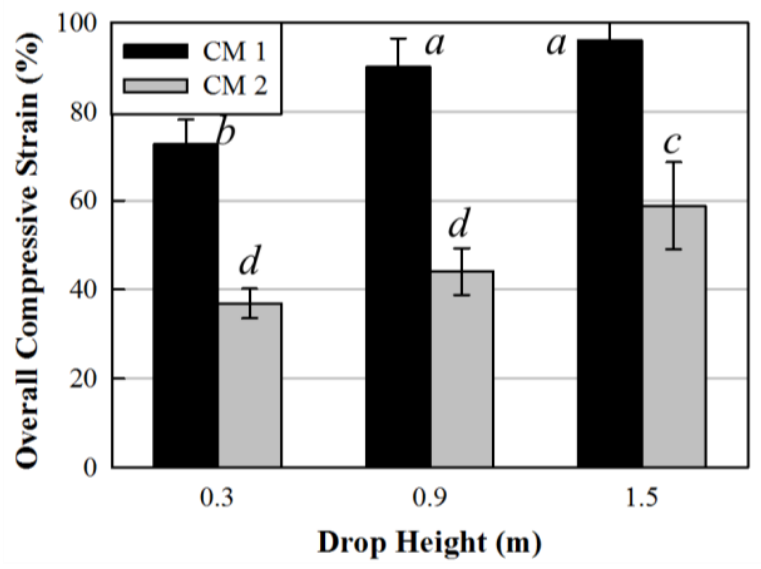

(Figure 3), where the stress keeps almost unchanged with the increase of deformation of a cushion material (Avalle et al., 2001). Therefore, to achieve good performance, it may require cushion materials have sufficient thickness to ensure that the maximum strain fall within the plateau region of the stress-strain curve. The average strain of cushion material 2 varied from 
6). Therefore, cushion material 2 had better capability of absorbing dynamic energy of cherries

321

322

323

324

325

326

327

328

329

330

331

332

333

334

335

336

337

338 than cushion material $1 \mathrm{did}$, especially at the drop height of more than $0.9 \mathrm{~m}$. On the other hand, cushion material 1 reached the strain level over $90.0 \%$ at the drop height of more than $0.9 \mathrm{~m}$, when the stress level increased dramatically for even a small change in strain. At this strain level, cushion material 1 behaved similar to metal catching surface at large drop height (e.g. $2.1 \mathrm{~m}$;

Figure 5). This result indicated that the thickness of a cushion material should be sufficient to keep the strain level less than $90.0 \%$ at the highest desired energy level to have cushion function.

\subsection{Assessment of fruit damage}

3.2.1 The effect of drop height on bruise damage

Fruit bruise damage due to mechanical impact during harvesting is determined by fruit variety, firmness and weight (Van linden et al., 2006a; Li and Thomas, 2014 ), as well as drop height and catching surface (Ortiz et al., 2011). To study the effect of external factors on bruise damage, a regression test of bruise area to multiple factors of drop height, fruit weight, fruit firmness, and maximum impact force was performed in SAS ${ }^{\circledR}$ procedure "REG". According to the analysis results of three catching surfaces at $0^{\circ}$ tilt angle (horizontal), only the factor of drop height had the significant effect on the bruise area $(p=0.01,0.00$ and 0.00 for cushion material 1 , cushion material 2 and non-cushion material respectively). This is because we randomized the fruit samples and there was no significant difference in the factors of fruit weight and firmness among different sample groups (Table 1).

Fruit damage percentage and average bruise area of each sample group at various drop heights on different catching surfaces were calculated and shown in Figure 7. From Figure 7a one can find that the catching surface with non-cushion material resulted in a bruise damage 
343 percentage of $83.3 \%$ at drop height of $0.6 \mathrm{~m}$ and $100.0 \%$ at the drop height of $1.2 \mathrm{~m}$ and above.

344 When a cushion material was padded over a non-cushion material, it reduced both the damage

345 percentage and bruise area noticeably. The figure also shows that when cushion material 1 was

346 used, it could keep the damage percentage under $10.0 \%$ when the fruit were dropping from $0.6 \mathrm{~m}$

347 or lower, and reached $16.0 \%$ and $75.1 \%$ at drop height of 1.2 and $2.1 \mathrm{~m}$ respectively. When a

348 firmer cushion material 2 was used, no damage was found until drop height increased to $0.9 \mathrm{~m}$;

349 the damage percentage reached $4.9 \%$ and $28.0 \%$ at the drop heights of 1.2 and $2.1 \mathrm{~m}$,

350 respectively.

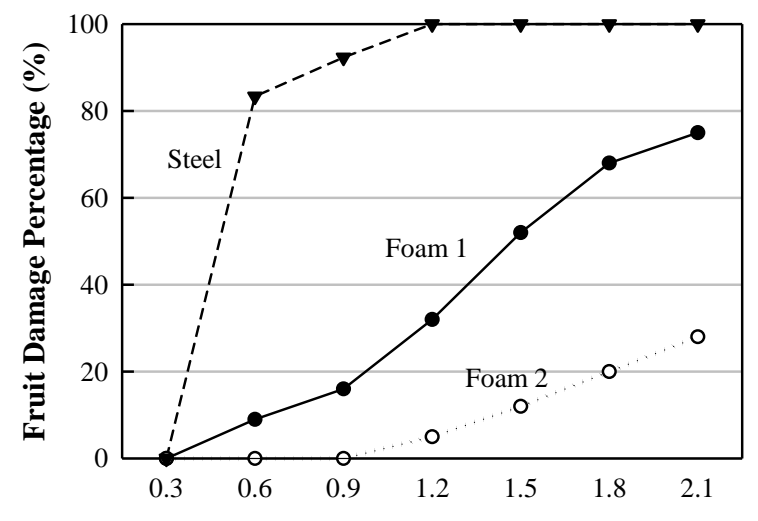

Drop Height (m)

(a) Fruit damage percentage

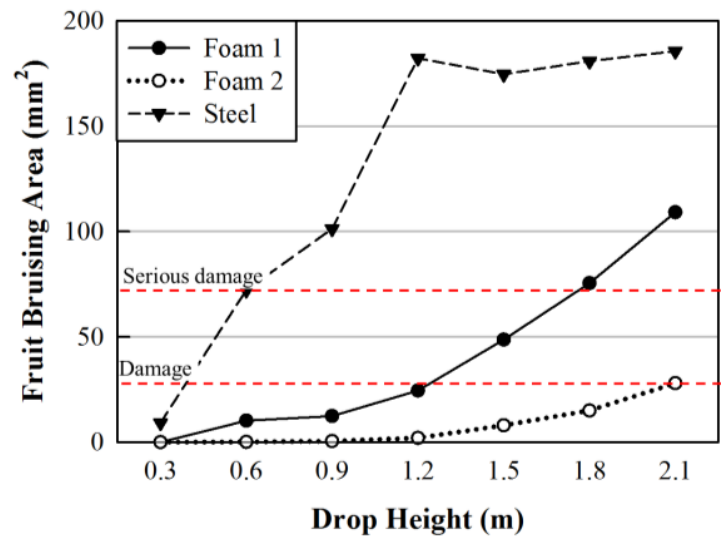

(b) Average bruise area of a sample group

Figure 7. Fruit damage percentage (a) and bruise area (b) with increasing drop height on different cushion materials. height when dropped onto different catching surfaces. In the figure, upper and lower dashed lines

357 show the threshold bruise area of damaged and serious damaged fruit, respectively (USDA-AMS, 1997). Similar to the damage percentage, the non-cushion surface resulted in the largest average 359 bruise area increasing from $9.6 \mathrm{~mm}^{2}$ at $0.3 \mathrm{~m}$ to the maximum value of $182.2 \mathrm{~mm}^{2}$ at $1.2 \mathrm{~m}$ and above. It is found that the bruise area kept almost unchanged at the drop height higher than $1.2 \mathrm{~m}$, which might because that almost half area of a fruit was bruised and the additional bruise area 
362 could not be counted based on the current method for measuring bruise area. As expected, the

363 average bruise area of fruits dropped on cushion materials was substantially smaller than that on

364 non-cushion surface. Although the cushion material 1 with less firmness had smaller impact

365 force at drop height of lower than $0.9 \mathrm{~m}$ (Figure 5), the significantly larger compressive strain

366 (deformation, as shown in Figure 6) resulted in more bruise area than that of cushion material 2.

367 Therefore, the first important factor of selecting cushion materials should be sufficient thickness

368 to ensure the compressive strain less than $90.0 \%$ at the highest drop height. It can be seen from

369 the figure that there was no bruise damage when using cushion material 2 below the drop height

370 of $0.9 \mathrm{~m}$, where the compressive strain was $44.0 \%$. The result confirmed that the choice of a

371 proper cushion material for fruit catching surface could effectively reduce both the bruise

372 damage percentage and bruise area induced by mechanical impact.

373

374

375

3.3.2 The effect of tilt angle on fruit bruise damage

The effect of tilt angle of a catching surface on the fruit bruise damage was shown in

377 damage substantially in both damage rate and bruise area. The most obvious reduction trend was

378 found in the non-cushion material at the drop height of more than $0.3 \mathrm{~m}$ (Figure 8a), where the

379 fruit damage percentages decreased constantly with the tilt angle increasing from $0^{\circ}$ to $60^{\circ}$. At

380 the drop height of $1.5 \mathrm{~m}$, the catching surface at $60^{\circ}$ saved approximate $50.0 \%$ of fruit from

381 being bruised comparing to catching surface at $0^{\circ}$. At the drop height of $0.9 \mathrm{~m}$, the fruit damage

382 percentage decreased from $92.3 \%$ at $0^{\circ}$ to $21.0 \%$ at $60^{\circ}$ accounting for a reduction of $77.0 \%$. The

383 effect of tilt angle in non-cushion material was also substantial in bruise area, as shown in Figure

$3848 \mathrm{~b}$. The average bruise area of fruits dropped from $1.5 \mathrm{~m}$ height decreased from $189 \mathrm{~mm}^{2}$ at $0^{\circ}$ to

$38588 \mathrm{~mm}^{2}$ at $60^{\circ}$ tilt angle. Although the average bruise area of fruit from lower drop height (0.3 to 
$0.9 \mathrm{~m}$ ) was fluctuating with the increasing tilt angle, the bruise area at $60^{\circ}$ was still the smallest.

Therefore, the catching surface at tilt angle of $60^{\circ}$ might reduce the bruise damage level

substantially and provide a potential method to safely catch cherry fruitS during mechanical harvesting when a sufficient small fruit drop height is difficult to pursue.

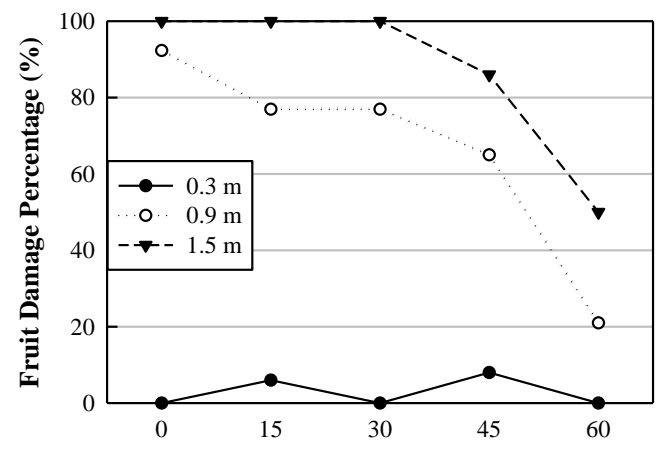

Tilt Angle (degree)

(a) Fruit damage percentage of non-cushion surface

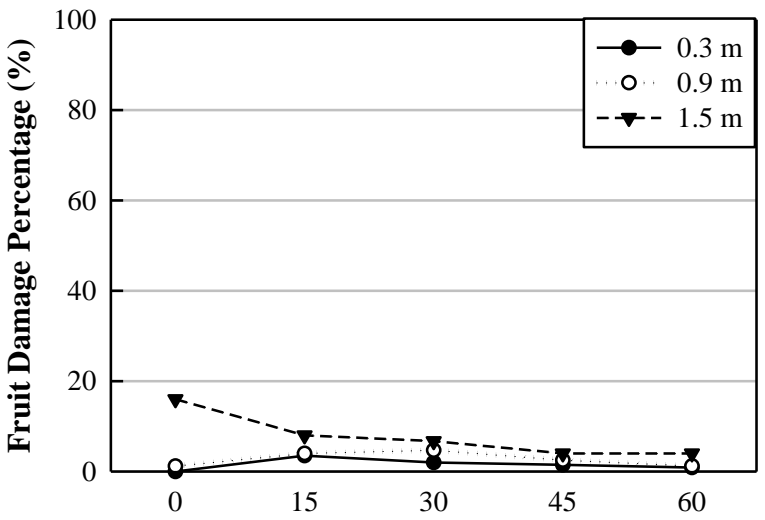

Tilt Angle (degree)

(c) Fruit damage percentage of cushion material 2

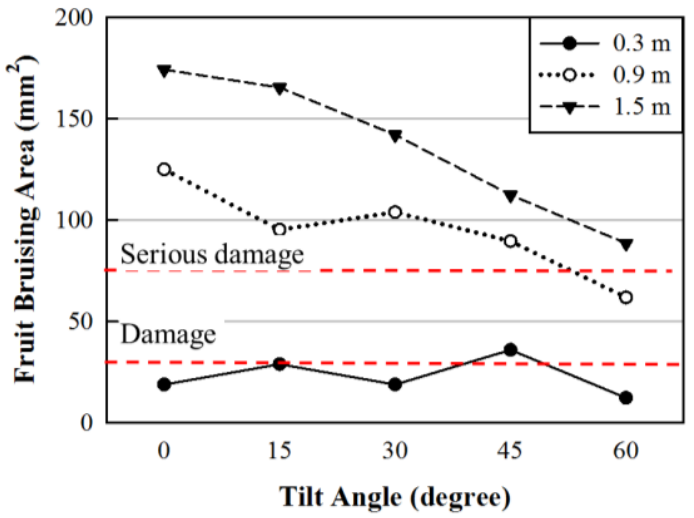

(b) Fruit bruise area of non-cushion surface

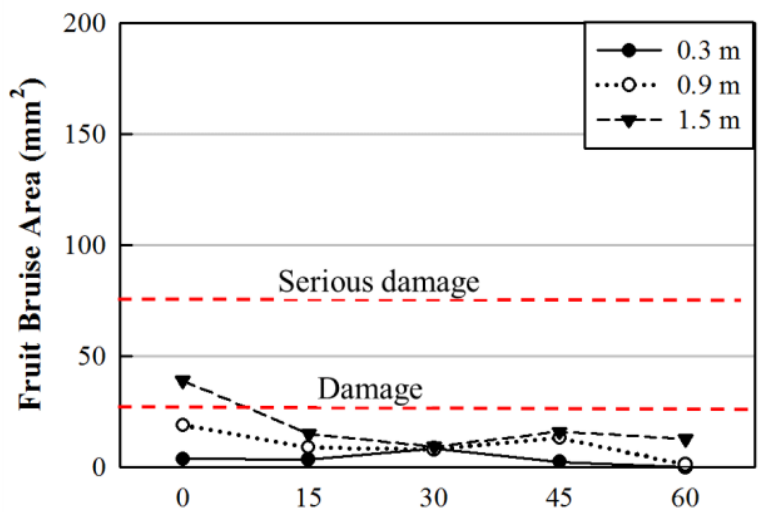

Tilt Angle (degree)

(d) Fruit bruise area of cushion material 2

Figure 8. Fruit damage percentage and bruise area over different drop heights and tilt angles based on the non-cushion surface and cushion material 2.

The damage percentage and bruise area of cushion material 2 at different tilt angles are shown in Figure 8c-d which show that the both indicators were also reduced by the tilt angle of catching surface at higher drop heights. Comparing to horizontal catching surface, catching surface at tilt angle of $60^{\circ}$ reduced damage percentage from $16.0 \%$ to $4.0 \%$ at $1.5 \mathrm{~m}$ drop height, accounting for a reduction of $75.0 \%$. Since very less fruits were damaged at the drop heights of 
$0.9 \mathrm{~m}$ and lower, the effect of tilt angle was not significant in those treatments. For bruise area, the catching surface with tilt angles also reduced the average bruise area in drop height of $0.9 \mathrm{~m}$ and above. Therefore, similar as non-cushion surface, cushioned materials with tilt angle of $60^{\circ}$ could also efficiently reduce fruit damage. However, the less fruit damage was caused by less energy absorption of the cushion material, may lead to higher rebounding velocity and multiple rebounding, which may result in additional mechanical impacts. The impact of multiple rebounding on fruit damage will be the subject of future investigation.

\section{Conclusion}

This paper investigated the effect of cushion material, fruit drop height and tilt angle of catching surface on bruise damage of sweet cherry fruit during mechanical harvest. A laboratory test platform was developed to measure the maximum impact force and deformation of cushion materials when fruits were dropped from several pre-defined heights and caught by catching surfaces. Three types of catching surface tilted at five angles were tested to study the effect of cushion material and tilt angel on fruit damage by correlating with the corresponding fruit damage defined as damage percentage and bruise area. The follows conclusions were achieved based on the results.

1. Cushion materials might substantially reduce the maximum impact force comparing to non-cushioned material, and thus could reduce fruit bruise damage when they had sufficient thickness.

2. Fruit bruise damage was significantly affected by fruit drop height. Fruit damage percentage increased substantially from no damage at the drop height of $0.3 \mathrm{~m}$ to $75.0 \%$ (cushion material 1) or $28.0 \%$ (cushion material 2) at drop height of $2.1 \mathrm{~m}$. 
3. The tilt angle of catching surface affected the bruise damage dramatically. The fruit bruise damage at $60^{\circ}$ tilt angle might cause a $70.0 \%$ reduction comparing to that of horizontal catching surface.

\section{Acknowledgments}

This research was supported in part by Washington State University Agricultural

Research Center federal formula funds, Project No. WNP0745 and No. WNP0728, received from the U.S. Department of Agriculture National Institutes for Food and Agriculture (NIFA) and by the USDA Special Crop Research Initiative (SCRI) program (Project No. WPN03320). Any opinions, findings, conclusions, or recommendations expressed in this publication are those of the authors and do not necessarily reflect the view of the U.S. Department of Agriculture and Washington State University. The authors would also like to express our gratefulness to Mr. Patrick Scharffor his help in the fabrication of experiment equipment.

\section{Reference}

Adrian, P. A., R. B. Fridley, and C. Lorenzen. 1965. Forced vibration of a tree limb. Transactions of the ASAE 8(4):473-475.

Ahmadi, E., H. R. Ghassemzadeh, M. Sadeghi, M. Moghaddam, and S. Z. Neshat. 2010. The effect of impact and fruit properties on the bruising of peach. Journal of Food Engineering 97:110-117.

Ampatzidis, Y. G., and M. D. Whiting. 2013. Training System Affects Sweet Cherry Harvest Efficiency. HortScience 48(5):547-555. 
Avalle, M., G. Beligardi, and R. Montanini. 2001. Characterization of polymeric structural foams under compressive impact loading by means of energy-absorption diagram. International Journal of Impact Engineering 25(5):455-472.

Brown, G. K., N. L. Schulte, E. J. Timm, R. M. Beaudry, D. L. Peterson, J. F. Hancock, and F. Takeda. 1996. Estimates of mechanization effects on fresh blueberry quality. Applied Engineering in Agriculture 12:21-26.

Chen, D., X. Du, Q. Zhang, M. D. Whiting, P. A. Scharf, and S. Wang. 2012. Performance evaluation of mechanical cherry harvesters for fresh market grade fruits. Applied Engineering in Agriculture 28:483-489.

Clark, R. L. 1971. The development of low-impact fruit catching surfaces. Transactions of the ASAE 14(4):608-611.

Erdoğan, D., M. Güner, E. Dursun, and İ. Gezer. 2003. Mechanical harvesting of apricots. Biosystems Engineering 85(1):19-28.

Halderson, J., L. 1966. Fundamental factors in mechanical cherry harvesting. Transactions of the ASAE 9(5):681- 684.

Hampson, C. R., K. Stanich, D. L. McKenzie, L. Herbert, R. Lu, J. Li, and M. A. Cliff. 2014. Determining the optimum firmness for sweet cherries using Just-About-Right sensory methodology. Postharvest Biology and Technology 91(2014):104-111.

Horsfield, B. C., R. B. Fridley, and L. L. Claypool. 1972. Application of theory of elasticity to the fruit harvesting and handling equipment for minimum bruising. Transactions of the ASAE 15(4):746-750. 
Jarimopas, B., S. P. Singh, S. Sayasoonthorn, and J. Singh. 2007. Comparison of package cushioning materials to protect post-harvest impact damage to apples. Packaging Technology and Science 20(5): 315-324.

Jiménez-Jiménez, F., S. Castro-García, G. L. Blanco-Roldán, L. Ferguson, U. A. Rosa, and J. A. Gil-Ribes. 2013. Table olive cultivar susceptibility to impact bruising. Postharvest Biology and Technology 86(0):100-106.

Markwardt, E. D., R. W. Guest, J. C. Cain, and R. L. LaBelle. 1964. Mechanical cherry harvesting. Transactions of the ASAE 7(1):70 - 74.

McMaster-Carr. 2013. Foam firmness. Available at: www.mcmaster.com. Acessed 12 October 2013.

Mezzetti, B. 2013. EUBerry: The sustainable improvement of European berry production, quality, and nutritional value in a changing environment. International Journal of Fruit Science 13(1-2):60-66.

Norton, R. A., L. L. Claypool, S. J. Leonard, P. A. Adrian, R. B. Fridley, and F. M. Charles. 1962. Mechanical harvest of sweet cherries. California Agriculture 16(5): 8-10.

Opara, U. L., and P. B. Pathare. 2014. Bruise damage measurement and analysis of fresh horticultural produce - A review. Postharvest Biology and Technology 91:9-24.

Opara, L. U., A. Al-Ghafri, H. Agzoun, J. Al-Issai, and F. Al-Jabri. 2007. Design and development of a new device for measuring susceptibility to impact damage of fresh produce. New Zealand journal of crop and horticultural science 35(2):245-251.

Ortiz, C., J. Blasco, S. Balasch, and A. Torregrosa. 2011. Shock absorbing surfaces for collecting fruit during the mechanical harvesting of citrus. Biosystems Engineering 110(1): 2-9. 
Pellerin, R. A., W. F. Millier, J. A. Throop, A. N. Lakso, and S. G. Carpenter. 1982. Apple harvesting with a double impact trunk shaker. Transactions of the ASAE 25(6):1567-1574.

Peterson, D. L., and G. K. Brown. 1996. Mechanical Harvester for Fresh Market Quality Blueberries. Transactions of the ASAE 39(3):823-827.

Peterson, D. L., M. D. Whiting, and S. D. Wolford. 2003. Fresh-market quality tree fruit harvester part I: sweet cherry. Applied Engineering in Agriculture 19(5):539-543.

Polat, R., I. Gezer, M. Guner, E. Dursun, D. Erdogan, and H. C. Bilim. 2007. Mechanical harvesting of pistachio nuts. Journal of Food Engineering 79(4):1131-1135.

Schrader, L. 2005. Improving cherry fruit quality and postharvest shelf life. Final project report. Accessed at: $\underline{\text { www.tfrec.wsu.edu. }}$. Accessed on: December 20, 2015.

Thompson, J. F., J. A. Grant, E. M. Kupferman, and J. Knutson. 1997. Reducing sweet cherry damage in postharvest operations. HortTechnology 7(2):134 - 138.

Torregrosa, A., B. Martín, C. Ortiz, and O. Chaparro. 2006. Mechanical Harvesting of Processed Apricots. Applied Engineering in Agriculture 22(4):499-506.

USDA-AMS. 1997. United States Standards for Grades of Sweet Cherries. Washington, D.C.: USDA Agricultural Marketing Service. Available at: www.ams.usda.gov. Accessed 23 September 2014.

USDA-AMS. 1990. Sweet Cherries: Visual Aid. Washington, D.C.: USDA Agricultural Marketing Service. Available at: www.ams.usda.gov. Accessed 23 September 2014.

USDA-AMS. 2005. Sweet Cherries: Shipping Point and Market Inspection Instructions. Washington, D.C.: USDA Agricultural Marketing Service. Available at: www.ams.usda.gov. Accessed 23 September 2014. 
511 USDA-ERS. 2012. Fruit and Tree Nuts Outlook. Washington, D.C.: USDA Agricultural

512 Marketing Service. Available at: www.ers.usda.gov. Accessed 23 September 2014.

513 Van linden, V., B. De Ketelaere, M. Desmet, and J. De Baerdemaeker. 2006. Determination of

514 bruise susceptibility of tomato fruit by means of an instrumented pendulum. Postharvest

$515 \quad$ Biology and Technology 40(1): 7-14.

516 Van linden, V., N. Scheerlinck, M. Desmet, and J. De Baerdemaeker. 2006. Factors that affect

517 tomato bruise development as a result of mechanical impact. Postharvest Biology and

518 Technology 42(3): 260-270.

519 Xu, R., F. Takeda, G. Krewer, and C. Li. 2015. Measure of mechanical impacts in commercial

520 blueberry packing lines and potential damage to blueberry fruit. Postharvest Biology and

$521 \quad$ Technology 110:103-113.

522 Yang, W., J. Harpole, C. Finn, and B. Strik. 2008. Evaluating berry firmness and total soluble

523 solids of newly released highbush blueberry cultivars. In IX International Vaccinium

524 Symposium. Acta Hort. 810.

525 Zhou, J., L. He, Q. Zhang, X. Du, D. Chen, and M. Karkee. 2013. Evaluation of the influence of

526 shaking frequency and duration in mechanical harvest of sweet cherry. Applied

$527 \quad$ Engineering in Agriculture 29(5):607 - 612.

528 Zhou, J., L. He, Q. Zhang, and M. Karkee. 2014. Effect of excitation position of a handheld

529 shaker on fruit removal efficiency and damage in mechanical harvesting of sweet cherry.

530 Biosystems Engineering 125(2014):36-44. 